\title{
El derecho de los pueblos indígenas a la libre determinación en el derecho internacional
}

\section{The right of indigenous peoples to self-determination in international law}

Pedro Mauricio Galarza Quezada, Ph.D

Universidad de la Amistad de los Pueblos de Rusia, Rusia

Hayk Paronyan, Ph.D

Universidad Regional Autónoma de los Andes-UNIANDES, Ecuador

Autor para correspondencia: pedro_galarza@mail.ru, hayk.paronyan@gmail.com

Fecha de recepción: 08 de noviembre de 2017 - Fecha de aceptación: 30 de noviembre de 2017

\section{Resumen}

El artículo tiene como objetivo analizar las principales tendencias hacia la implementación del derecho de autodeterminación de los pueblos indígenas tanto a nivel regional (Sistema Interamericano de Derechos Humanos) como internacional (El sistema de derechos humanos de la ONU). Se ha prestado especial atención a la interpretación de este derecho en diferentes documentos, como el Convenio 169 de la OIT, la Declaración de las Naciones Unidas sobre los derechos de los pueblos indígenas, la Declaración Americana sobre los Derechos de los Pueblos Indígenas, etc. De esta manera, se han considerado diferentes aspectos del derecho de los pueblos indígenas a la autodeterminación desde la perspectiva del derecho internacional. En conclusiones, este estudio ha identificado medidas y desafíos relacionados con los esfuerzos necesarios para asegurar la implementación de este derecho.

Palabras clave: pueblos indígenas; derecho a la autodeterminación; sistema Interamericano de derechos humanos; sistema de derechos humanos de la ONU; derecho internacional

\begin{abstract}
The article aims to analyze the main trends towards the implementation of the indigenous peoples' right to self-determination both at regional (The Inter-American System of Human Rights) and international levels (The UN human rights system). Special attention has been paid to the interpretation of this right in different documents, such as ILO Convention 169, the UN Declaration on the rights of indigenous peoples, The American Declaration on the Rights of Indigenous Peoples, etc. In this way, different aspects of the indigenous peoples' right to selfdetermination has been considered from the perspective of international law. In conclusions this study has identified the measures and challenges related to the efforts needed to ensure the implementation of this right.
\end{abstract}

Key words: indigenous peoples; right to self-determination; The Inter-American System of Human Rights; The UN human rights system; international law 


\section{Introducción}

Analizando el problema de la auto-determinación de los pueblos indígenas, nos enfrentamos a un gran desafío. La gran mayoría de los pueblos indígenas, como se ha señalado en la literatura científica extranjera, todavía se encuentra en una "situación colonial interna", o a su vez tienen la condición de "naciones internas dependientes" no obstante el enfoque realista a la cuestión de la soberanía y la autodeterminación de estos se obstaculizan en el sentido amplio de la palabra (Nettheim, 1988). Así como la concepción misma de la autodeterminación no es aplicada en forma estricta. Además, los pueblos indígenas hoy en día ya no son tratados como naciones coloniales teniendo el derecho a la libre determinación de conformidad con los instrumentos jurídicos internacionales, en ausencia del colonialismo en su sentido clásico (Anaya, 2004, p. 110).

Al mismo tiempo, las poblaciones aborígenes con firmeza insisten en la estrecha relación entre sus derechos inalienables a sus territorios y su derecho paralelo a la gestión de autodeterminación. Esta relación ha sido reconocida, y ha sido instaurado un gobierno autónomo sólo en dos partes del Mundo actual. La primera Groenlandia - una antigua colonia danesa, que hasta hace unas décadas fue reconocida parte de Dinamarca. El segundo ejemplo es Nunavut en el norte de Canadá, que fue establecido como un territorio autónomo en 1993. En otros países, los pueblos indígenas están demandando a sus gobiernos para la restauración de sus derechos a su territorio y, al mismo tiempo impugnan la lucha para la reactivación de las instituciones políticas.

\section{La autodeterminación de los pueblos indígenas}

El Artículo 1 de la Convención de Montevideo sobre Derechos y Deberes de los Estados establece los criterios principales para determinar el estado de requisitos necesarios para la creación de un estado: una población permanente, un territorio definido, un gobierno y la capacidad efectiva para entrar en relaciones con otros estados (1933). Por lo tanto, los pueblos y naciones que potencialmente cumplen con estos criterios, pueden crear su propio estado y tienen el derecho a la libre determinación, incluida la opción de la independencia. Las naciones que no cumplen estas exigencias, también tienen el derecho a la autodeterminación, pero no más allá de los límites de la autonomía, es decir, en el marco de otra nación (Clinebell \& Thomson, 1978, p. 669). Ciertamente el criterio del derecho a la libre determinación se rige a los cuatro puntos anteriores, podemos ver que un gran número de pueblos indígenas responden plenamente a estos criterios, asumiendo que todas las tierras ancestrales de propiedad de naciones indígenas como se proclama en los instrumentos internacionales son de su histórica propiedad.

Las demandas aborígenes para la aplicación del derecho a la libre autodeterminación causo sorprendente reacción de muchos gobiernos, tal cual el requisito de libre determinación es a menudo identificado con los requisitos de independencia y secesión. Más tarde muchos países influyentes han sido capaces de superar sus inconveniencias y más bien han apoyado la idea de la libre determinación interna. Así como Dinamarca a finales de los años 70 para conceder autonomía a los esquimales de Groenlandia y Canadá reconocido a finales de los 90 una autonomía limitada para los inuitas del norte de Canadá y nisga'a Popular de Columbia Británica. En 1996, Canadá afirmó durante la discusión del proyecto de Declaración, que reconoce el 
derecho de libre determinación de los pueblos indígenas, respetando la integridad política, constitucional y territorial de los Estados democráticos, siempre y cuando este derecho se implemente a través de negociaciones entre los Estados y los nativos. Nueva Zelanda y Noruega han acordado que la autodeterminación es el elemento más importante en el proyecto de declaración. Sin embargo, junto con Finlandia, propusieron distinguir claramente entre los aspectos internos y externos basados en el hecho de que la autodeterminación interna se realiza por medio de negociaciones entre el gobierno y las poblaciones indígenas.

Un poco antes, en 1975, hubo un avance histórico decisivo en el reconocimiento jurídico internacional de los derechos de los pueblos indígenas. La Corte Internacional de Justicia notificó que los indígenas del Sahara Occidental tienen derecho a la libre determinación, como una alternativa a la inclusión obligatoria en el estado. Así mismo en 1983, un juez de la Corte Internacional de Justicia, Robert Jennings se refirió al caso de "Sahara Occidental", como un precedente importante, lo que demuestra que en el enfoque del derecho internacional para la comunicación entre las comunidades con la tierra es completamente diferente del enfoque adoptado en la ley de tierras del oeste, que se basa en la posesión y uso de terrenos sujetos en relación con la adquisición y el ejercicio de la soberanía sobre el territorio. Insistió en que el derecho internacional debe incluir la totalidad de las tradiciones legales del mundo, e hizo hincapié en la necesidad urgente para el desarrollo del derecho internacional, la capacidad de cubrir todas las diferentes culturas y civilizaciones (Schwebel. 1996).

En el caso de "Sahara Occidental" hay dos aspectos fundamentales. En primer lugar, el reconocimiento ilegal de la utilización del término jurídico «terra nullius» (tierra de nadie) para referirse al territorio ocupado por los indígenas. En segundo lugar, el caso de "Sahara Occidental" como un nuevo precedente en el derecho internacional afirmó la importancia histórica de las negociaciones que llevaron a la conclusión de acuerdos entre las autoridades del gobierno y los pueblos indígenas para expandir su territorio.

En 1999, el Grupo de Trabajo sobre Poblaciones Indígenas presentó un informe de evaluación de los tratados y acuerdos previamente firmados entre los pueblos ancestrales y los gobiernos de los Estados. El informe afirma el principio de que los tratados entre los aquellos pueblos y los Estados son tratados internacionales que los pueblos indígenas son sujetos de derecho internacional y cualquier intento por parte de las autoridades para hacer estos acuerdos de carácter de derecho interno y, en consecuencia, el carácter unilateral viola el derecho de los aborígenes al derecho de autodeterminación.

En la literatura de estados europeos y asiáticos también se puede encontrar la opinión de que la potenciación del derecho de los pueblos indígenas a la libre determinación puede ser una valiosa contribución al desarrollo del derecho internacional (Spaulding, 1997). Sin embargo, según el Convenio de la OIT con N.169 establece que el uso del término "pueblos" en la Convención no se interpretará y no tendrá implicación alguna en lo que respecta a los derechos que puedan conferirse a dicho término en el derecho internacional. De ello se desprende que el concepto de "pueblo" y "pueblos indígenas" no son equivalentes, y tienen una interpretación diferente en el derecho internacional. Esta reserva no se hizo por accidente, significa que la aplicación de los derechos aborígenes no implica el derecho de los pueblos a la libre determinación, a saber, el componente exterior, lo que implica la libre elección de estas naciones 
de su condición política y el aislamiento territorial para formar su propio estado. Es decir, instrumentos jurídicos internacionales que establecen el derecho de los pueblos a la libre determinación no se aplica a los pueblos indígenas.

Es por ello que el Convenio de la OIT de N. 107 firmado en 1957 ha utilizado el término "población indígena", en lugar de "pueblos indígenas" y la adopción de un nuevo convenio de la OIT con número 169 de 1989 que llevo a cabo fuertes debates dirigidos a establecer que término usar "gente" o "pueblos", ya que los gobiernos de muchos países mostraban preocupación por la posibilidad de que sus naciones ejercen el derecho de los pueblos a la autodeterminación (Swepston, 1989). Después de todo, el reconocimiento del derecho a la libre determinación, como base de los principios del derecho internacional, es un derecho inalienable de cada nación. Como resultado, se decidió utilizar la frase "pueblos indígenas", pero con la condición anterior.

\section{La autodeterminación y el sistema de los derechos humanos de la ONU}

De acuerdo con el Prof. Ananidze F.R. (1996), el derecho a la autodeterminación no significa la separación automática, la creación de un estado y la autodeterminación de los pueblos indígenas, respectivamente, en el mundo moderno debe ser reducida al derecho del desarrollo, es decir, la solución de los problemas socio-económicos, culturales, religiosos y políticos que enfrentan los pueblos indígenas en la actualidad. Después de todo, la ignorancia y la incapacidad para resolver los problemas anteriores en el estado sirven de fundamento para que los pueblos indígenas invoquen la separación. Como un ejemplo positivo en la política de Finlandia relativa a las islas Aland, es el ofrecimiento a los residentes de estas islas, los suecos, amplios derechos de autonomía, eliminando de este modo la tensión y resolver así el problema de la separación.

Los Estados deben prestar especial atención a los gobiernos locales, dando a los pueblos indígenas el derecho a resolver sus propios problemas a través de los órganos de gobierno locales, así como a través del gobierno local o el parlamento. Todo esto servirá como un entorno político y legal importante para la supervivencia, la conservación y el desarrollo de los pueblos indígenas. En este sentido, hay que citar las conclusiones y recomendaciones de la Reunión de Expertos de las Naciones Unidas sobre cuestiones de la autonomía y la autonomía interna de los pueblos indígenas, celebrado en Nuuk, Groenlandia, 1991 (Rouland, Pierré-Caps, Poumarede, 1999):

- Las poblaciones indígenas son históricamente autónomas que cuentan con su propia lengua, cultura, leyes y tradiciones;

- Los pueblos indígenas son pueblos y sociedades distintas que tienen el derecho a la libre determinación, incluido el derecho a la autonomía, la autogestión y la identidad;

- La autogestión y la decisión independiente de las cuestiones administrativas y económicas de las poblaciones indígenas son elementos de autonomía política. El ejercicio de este derecho no debe poner en peligro la integridad territorial del Estado;

- La autonomía indígena y el autogobierno son requisitos previos para el logro de la igualdad, el respeto por la dignidad humana, la libertad de la discriminación y el pleno disfrute de todos los derechos humanos; 
- El territorio de los pueblos indígenas y sus recursos son esenciales para la realización física, cultural y espiritual de estos pueblos y para lograr, el efectivo ejercicio de la autonomía y el autogobierno. Este territorio y los recursos deben estar garantizados por los pueblos por su existencia y el desarrollo constante de las comunidades y culturas indígenas;

- La autonomía y el autogobierno de los pueblos indígenas tienen un valor favorable para la protección del medio ambiente;

- Autonomía y auto-gobierno cuerpos de los pueblos indígenas deben estar dentro del marco de su competencia, para asegurar el pleno disfrute de todos los derechos humanos y las libertades fundamentales y la participación popular en los asuntos públicos;

- La base de la autonomía y el autogobierno se puede basar en los tratados internacionales, la Constitución o la legislación, reconocen los derechos de los pueblos indígenas. También es necesario asegurarse de que los tratados, convenios y otros acuerdos específicos con diversas circunstancias históricas, tales como la creación de documentos y confirmar el marco legal y territorial de los derechos de los pueblos indígenas a la autonomía y el autogobierno;

- La autonomía y el autogobierno son esenciales para la supervivencia y el desarrollo de los pueblos indígenas y sirven como base para la cooperación internacional y los acuerdos legales bilaterales y multilaterales;

- En el marco de la autonomía estatal y la autonomía de los pueblos indígenas contribuir al desarrollo político, cultural, espiritual, social y económico pacífico y equitativo;

- Sujeto a los deseos libremente expresados de la autonomía de los pueblos indígenas y la autonomía comprende, en particular, la competencia para adoptar decisiones, o activamente y participar de manera efectiva en este proceso sobre las cuestiones relativas a su tierra, los recursos, el medio ambiente, el desarrollo, la justicia, la educación, la información y la comunicación, la cultura, la religión, la salud, la vivienda, la seguridad social, el comercio, los sistemas económicos tradicionales, etc.; -el acuerdo sobre la autonomía y el autogobierno estará sujeta a la observancia de la buena fe.

La Declaración sobre los Derechos de los Pueblos Indígenas, aprobada por la Asamblea General de la ONU en el 2007, contiene una disposición que el Estado debe respetar el derecho de los pueblos indígenas a la libre determinación interna y buscar los medios necesarios para la financiación de actividades dirigidas a la consecución y realización de la autodeterminación. Además, antes de tomar cualquier acción en relación con los intereses de los pueblos indígenas, el gobierno debe obtener el consentimiento expreso de los pueblos indígenas, sobre la base de la presentación previa de la información objetiva. El documento impone al Estado la obligación de llevar a cabo conjuntamente con los pueblos indígenas, medidas para aplicar plenamente el derecho a la autodeterminación. Al mismo tiempo, el artículo 46 de la Declaración establece que nada en esta Declaración podrá interpretarse o considerarse como instrumento que autoriza o fomenta acción alguna encaminada a quebrantar o a la interrupción parcial o total de la integridad territorial o la unidad política de Estados soberanos e independientes.

Ciertamente revolucionario en el derecho internacional puede ser el tema de la situación de garantizar el derecho a la libre determinación "interna" para los pueblos indígenas. De este modo, la Declaración de las Naciones Unidas sobre los Derechos de los Pueblos Indígenas proclamando el derecho de los pueblos indígenas a la libre determinación "interna", al mismo tiempo establece la forma y los límites de la realización de este derecho. De esta manera al esbozar una gama bastante amplia sobre los derechos de los pueblos indígenas, y al mismo 
tiempo la fijación de los límites de su aplicación, la Declaración, por lo tanto, establece las obligaciones respectivas del Estado, que deben ser considerados como responsables de la aplicación de tales derechos. En este sentido, la Declaración puede considerarse suficientemente específica, equilibrada y progresiva. Se fija claramente la existencia del derecho a la libre determinación interna de los pueblos indígenas y la falta de ese derecho a la libre determinación externa.

El logro de la Declaración y, en nuestra opinión, constituye la ausencia de las mencionadas reservas, en el Convenio de la OIT número 169 con respecto al término "pueblo". El debate en los círculos científicos, si dirige a que, si los indígenas forman parte de su propia nación, así como el "análisis" que si los indígenas son personas. En nuestra opinión, la reserva a la Convención № 169 es discriminatoria, es la misma cosa que reconocer a los indígenas, pero al mismo tiempo les priva de todos los derechos derivados de este concepto.

Existe un problema evidente: algunos pueblos indígenas quieren definirse a sí mismos hasta la secesión y la creación de un Estado-nación independiente, por ejemplo, algunas tribus indias en los Estados Unidos y Canadá, lo que inevitablemente implicaría una violación de la integridad territorial del estado. Otros - están de acuerdo en vivir bajo el estado actual del gobierno nacional sobre las condiciones, tales como los pueblos indígenas rusos. Y la mayoría de los pueblos indígenas no buscan la secesión de los estados existentes, sino que requieren que los estados, en principio, no tengan autoridad para dictar de antemano leyes y normas a los aborígenes, ya que ellos decidirán su propio destino. El profesor James Anaya (1991), asevera además que las exigencias de los pueblos indígenas de Estados Unidos sobre la no discriminación y la igualdad de trato de todos los miembros del pueblo en el contexto del desarrollo social, no se limitan en esto, sino que piden una separación y autonomía con respecto a otro estado de residencia de la población.

En este contexto, hay que citar la decisión del Comité de Derechos Humanos de la ONU, en relación a Chile del 26 de marzo de 2007. El Comité de Derechos Humanos, resalto las opiniones expresadas por el gobierno sobre la intención de orden Constitucional para consolidar el estado de las poblaciones indígenas, expreso la preocupación acerca de los diferentes mensajes de consistente insatisfacción por los pueblos indígenas, al no cumplir con algunos de los requisitos de estos especialmente de los indios mapuches, así como la lentitud de la demarcación de las tierras indígenas creando de esta manera tensiones sociales. El Comité expresó su molestia y desacuerdo por los informes de que las "tierras ancestrales" continúan amenazadas por la expansión y la ejecución de proyectos a gran escala en infraestructura y energía forestal.

El Comité recomendó realizar todos los esfuerzos posibles para asegurar que las negociaciones con las comunidades indígenas que proporcionan la solución del cumplimiento de los derechos sobre las tierras de estas comunidades se encuentran inscritos en el punto 2 del artículo 1 y el artículo 27 del Pacto Internacional de Derechos Civiles y Políticos, así como para acelerar el proceso de reconocimiento de las tierras ancestrales; de igual recomendó modificar su legislación para ponerla en conformidad con el artículo 27 del Pacto Internacional y revisar la legislación sectorial, cuyo contenido puede ser contraria a los derechos consagrados en el Pacto. También se recomienda consultar con las comunidades indígenas antes de conceder licencias para la explotación económica de las tierras objeto de controversia y garantizar que dichas 
explotaciones bajo cualquier circunstancia no conduzcan a un incumplimiento reconocido en los derechos del Pacto Internacional. Por lo tanto, el Comité aclaró su posición con respecto a la interpretación y aplicación del artículo 1 del Pacto.

A pesar de las disposiciones en contrario de los instrumentos jurídicos internacionales, que han garantizado el derecho de los pueblos a la libre determinación, que no nos permiten afirmar que todos los pueblos, es decir, y de los pueblos indígenas en particular, tienen derecho a la autodeterminación. La única cuestión es que en el momento actual los pueblos indígenas están privados de la dimensión externa del derecho a la autodeterminación, mientras que la parte interna de la misma pertenece a todas las naciones sin excepción. De acuerdo con los investigadores rusos, para resolver el problema de la autodeterminación de los pueblos indígenas variante o modelo de autodeterminación sin la separación aceptable para los pueblos indígenas, y para los Estados-nación (Abashidze \& Ananidze, 1997, p. 142). De hecho, este enfoque es visto como el más equilibrado, ya que permite tanto los intereses de los pueblos indígenas en particular, como los intereses del estado en el que reside. Este enfoque nos parece el más realista y aceptable.

\section{Las poblaciones indígenas y el Sistema Interamericano de Derechos Humanos}

En cuanto al sistema interamericano, existe una fuerte tendencia a reconocer el derecho a la libre determinación en los órganos de la OEA, relacionados con la protección de los derechos humanos. El 15 de junio de 2016, la Asamblea General de la Organización de los Estados Americanos (OEA) adoptó la Declaración Americana sobre los Derechos de los Pueblos Indígenas, después de décadas de laboriosas negociaciones. Aprobada casi diez años después de la Declaración de las Naciones Unidas sobre los Derechos de los Pueblos Indígenas (DNUDPI), la Declaración Americana aborda asuntos que no fueron cubiertos por la DNUDPI, incluyendo situaciones específicas relevantes para la región como los derechos de los pueblos indígenas en “aislamiento voluntario" y los pueblos indígenas afectados por los conflictos armados (Declaración Americana, arts. XXVI, XXX).

Dicha Declaración regional también refuerza las disposiciones de la DNUDPI relativas a los derechos de los pueblos indígenas sobre tratados, que son particularmente relevantes para las Américas en formas que han sido consideradas como una "gran victoria" por algunos pueblos indígenas del hemisferio. Sin embargo, en otras esferas la Declaración no cumple con las normas establecidas en la DNUDPI o han sido desarrolladas por las instituciones regionales de derechos humanos.

Compuesta de cuarenta y un artículos divididos en seis secciones temáticas, la Declaración Americana reconoce una amplia serie de derechos individuales y colectivos considerados "indispensables para la existencia, el bienestar y el desarrollo integral de los pueblos indígenas" (Id. arts. XV, XVIII). De acuerdo con el artículo XLI, estos derechos constituyen las normas mínimas para la supervivencia, la dignidad y el bienestar de los pueblos indígenas de las Américas. De acuerdo con el enfoque comúnmente seguido en los otros instrumentos concernientes a los pueblos indígenas, la Declaración no proporciona ninguna definición del término "pueblos indígenas" sino que se basa en el criterio de auto identificación 
según las "prácticas e instituciones de cada pueblo indígena" para definir su ámbito de aplicación (Id. art. I).

En su Preámbulo, la Declaración reproduce algunos párrafos de la DNUDPI y recuerda las injusticias históricas sufridas por los pueblos indígenas, la necesidad urgente de respetar y promover sus derechos inherentes y la importancia de eliminar todas las formas de discriminación contra ellos. Sorprendentemente, sin embargo, no reconoce a los pueblos indígenas como pueblos "iguales a todos los demás pueblos", como lo había hecho la DNUDPI, haciendo explícito el vínculo entre los pueblos indígenas como pueblos y el derecho a la autodeterminación. Al hacerlo, la DNUDPI reconoce que los pueblos indígenas, al igual que otros pueblos, tienen pleno derecho a ejercer la libre determinación, incluso en su dimensión externa, si se cumplen las condiciones (Anaya, 2009).

Una declaración similar no se encuentra en la Declaración Americana, que se limita a afirmar que los pueblos indígenas tienen derecho a la autodeterminación, tomando prestado un lenguaje común del artículo 1 de los Pactos de las Naciones Unidas sobre Derechos Humanos y el artículo 3 de la DNUDPI, que establece que al ejercer este derecho, los pueblos indígenas tienen derecho a la autonomía o al autogobierno en asuntos internos y locales, reproduciendo de esta manera el Artículo 4 de la DNUDPI. Este derecho se entiende como un derecho a la autodeterminación interna, de acuerdo con los límites formulados en el artículo IV para salvaguardar "la integridad territorial o la unidad política de los Estados soberanos e independientes". A través de las diversas secciones temáticas, la Declaración establece así el derecho de los pueblos indígenas a mantener sus sistemas o instituciones jurídicos, sociales, políticos y económicos para que se reconozcan y respeten sus leyes y sistemas jurídicos indígenas para promover y desarrollar sus "sistemas y medios de comunicación", para mantener sus propios sistemas y prácticas de salud, establecer y controlar sus sistemas e instituciones educativas y determinar sus prioridades para el desarrollo y diseñar políticas, planes, programas y estrategias como consecuencia (La Declaración Americana, arts. VI, XXII; XXII).

La Declaración reconoce también en el artículo XXI el derecho de los pueblos indígenas a mantener y desarrollar sus propias instituciones de adopción de decisiones y participar en la adopción de decisiones sobre cuestiones que afecten a sus derechos. Además, se declara que los pueblos indígenas tienen derecho a la igualdad de oportunidades para acceder y participar de manera plena y efectiva como pueblos en todas las instituciones y foros nacionales, incluidos los órganos deliberativos (Id. art. XXI, p. 2.). Sin embargo, la Declaración no sigue plenamente el enfoque dual, apoyando a los principios de autogobierno y participación como expresiones de autodeterminación de los pueblos indígenas que sustentan la DNUDPI.

El artículo XXIII parece que limita el alcance de la participación de los pueblos indígenas a "asuntos que afectan a sus derechos y que están relacionados con el desarrollo y ejecución de leyes, políticas públicas, programas, planes y acciones referentes a los asuntos indígenas". Por otra parte, el artículo XXIII limita su participación y consulta presentando estos conceptos en el contexto de las "contribuciones de los sistemas jurídicos y organizativos indígenas". En cambio, como señaló el Relator Especial de la ONU sobre los derechos de los pueblos indígenas al referirse a las disposiciones de la DNUDPI y a otros instrumentos, los pueblos indígenas participarán en los procesos de toma de decisiones "siempre que una decisión del Estado afecte a 
los pueblos indígenas. Esto puede ocurrir "cuando los intereses o condiciones de los pueblos indígenas que son particulares a ellos están implicados en la toma de decisiones, incluso cuando la decisión puede tener un impacto más amplio, como en el caso de ciertas legislaciones (Anaya, 2009).

Algunos casos indican la posición de la Comisión y la Corte interamericana de Derechos Humanos. En 1980 hubo conflictos en Nicaragua entre los indios miskitos y el gobierno Sandinista debido a un nuevo programa de reforma agraria. Los miskitos creían que el programa no tenía en cuenta la propiedad indígena de muchas tierras distribuidas. Los Miskitos presentaron una denuncia ante la Comisión Interamericana de Derechos Humanos (1983), argumentando que debía garantizarse el derecho de su grupo a la tierra con sus recursos, así como el derecho a la libre determinación. Uno de los abogados de los indígenas afirmó que la comunidad tenía las cualidades que lo convertían en un Estado independiente: territorio, población, gobierno y capacidad para establecer relaciones internacionales (Engle, 2011). La Comisión reconoció que el derecho internacional garantiza el derecho a la libre determinación, pero que no sería aplicable en ese momento porque el Miskito no tenía independencia política (la Comisión interpretó la libre determinación como soberanía). Sin embargo, la decisión de la Corte no permitió a Nicaragua asimilar la cultura indígena. Más bien, el Estado debe tener que proteger todos los aspectos relacionados con la identidad cultural del pueblo.

Dos informes sobre Colombia subrayan la preocupación de la Comisión por proteger a los pueblos indígenas. En 1981, la Comisión recomendó que el gobierno colombiano tomara las medidas necesarias para la protección de los indígenas durante la ejecución de las operaciones militares. En 1993, la Comisión subrayó la importancia de la disposición constitucional de autonomía judicial de las autoridades indígenas para el desarrollo de la independencia de las minorías étnicas.

Además de la Comisión, la Corte Interamericana de Derechos Humanos juega un papel importante en la transformación de la realidad social. En cuanto a la autonomía de los pueblos indígenas, en los pueblos Aloeboetoe y otros contra Suriname (1993), la Corte se aseguró de que la existencia del derecho consuetudinario tribal prevalecería sobre las leyes de Suriname, siempre que no sea contraria a los términos de la Convención Americana.

En el pueblo de Saramaka v. Suriname (2007), la Corte reconoció el derecho de los pueblos indígenas a promover su propio desarrollo socioeconómico, a disponer libremente de las riquezas y recursos naturales y no ser privados de los medios de supervivencia. En Xákmok Kásek v. Paraguay (2010), la Corte afirmó la responsabilidad del Estado de reconocer y respetar la personalidad jurídica de la comunidad indígena y no violar su autodeterminación. Finalmente, en Kichwa Sarayaku v. Ecuador (2012), después de una larga batalla legal, la Corte decidió a favor de los pueblos indígenas y mencionó la Declaración de la ONU sobre los Derechos de los Pueblos Indígenas en apoyo a sus órdenes relacionadas con el derecho a previa consulta de los pueblos indígenas.

Entre los principios fundamentales de la República del Ecuador están la soberanía, interculturalidad y plurinacionalidad, así como el reconocimiento de las lenguas indígenas como lenguas oficiales para las relaciones interculturales y el deber del gobierno de promover la 
unidad nacional frente a la diversidad (artículos 1-3). El artículo 57 de la Constitución ecuatoriana contiene una larga lista de derechos colectivos de los pueblos indígenas. Los derechos más relevantes para la autodeterminación de los pueblos indígenas son los derechos de mantener y desarrollar sus propias formas de vida y organización social, crear y ejercer autoridad, promulgar y hacer cumplir su ley, establecer y mantener organizaciones representativas, participar en los órganos oficiales y en el desarrollo de las políticas públicas, para ser consultados antes de la adopción de una medida legislativa que pudiera afectarlos y el derecho a mantener y desarrollar relaciones de cooperación con otros pueblos.

\section{Conclusión}

El derecho a la autodeterminación de los pueblos indígenas desempeña un papel cada vez más central en el ordenamiento jurídico internacional. La Declaración de las Naciones Unidas sobre los Derechos de los Pueblos Indígenas reforzó la aspiración de que los pueblos indígenas y sus comunidades tuvieran derecho, entre otras cosas, a definir libremente sus formas de vida y culturas, a practicar sus lenguas y tradiciones. Respecto al sistema interamericano, existe una fuerte tendencia a reconocer el derecho a la libre determinación en los órganos de la OEA.

La autodeterminación es un derecho colectivo, limitado por los derechos humanos individuales considerado como una condición necesaria para la protección de los pueblos indígenas dentro de los Estados independientes, así como para el alojamiento de la diversidad étnica. El derecho a la autodeterminación se incorporó a los sistemas legales internos en muchos estados latinoamericanos, incluyendo Ecuador en las últimas dos décadas. Había, por tanto, una salida de las ideologías colonizadoras, que impulsaron la promoción de políticas de carácter asimilacionista o aislacionista.

La condición de vulnerabilidad o susceptibilidad a los riesgos que normalmente caracterizan a los pueblos indígenas requiere de los estados que garanticen que las comunidades puedan ejercer el derecho a la autodeterminación. La autodeterminación implica el reconocimiento de la capacidad individual y colectiva de los pueblos indígenas y que no deben ser tratados como incapaces o meros objetos de políticas públicas. Los estados deben otorgar a los pueblos indígenas autonomía y autogobierno, para que puedan decidir libremente si preservan, modifican o abandonan sus formas de vida ancestrales.

\section{Bibliografía}

Aloeboetoe y otros vs. Surinam, (1993) Recuperdo de http://www.corteidh.or.cr/docs/casos/articulos/seriec_15_esp.pdf

Ananidze, F. (1996) International legal problems of protection of rights Indigenous peoples. $\mathrm{PhD}$ thesis. Moscow: PFUR

Anaya, J. (1991) The Capacity of International Law to Advance Ethnic or Nationality Rights Claims. Human Rights Quarterly, Vol.13. № 3.

Anaya, J. (2009) International Human Rights and Indigenous Peoples, Aspen Publishers. 
Anaya, J.(2004) Indigenous Peoples in International Law. Second Edition. Oxford University Press

Clinebell, J., Thomson J. (1978) Sovereignty and Self-Determination: The Rights of Native Americans under International Law // Buffalo Legal Review, № 27.

Comision Interamericana de derechos humanos. Informe sobre la situación de los derechos humanos

de un sector de la población nicaragüense de origen Miskito OEA/Ser.L/V/II.62 doc. 10 rev. 3

29 noviembre 1983. Recuperado de http://www.cidh.org/countryrep/miskitosesp/indice.htm

Constitución de la República del Ecuador (2008) Recuperado de http://www.asambleanacional.gob.ec/sites/default/files/documents/old/constitucion_de_bolsillo .pdf

Declaración Americana sobre los Derechos de los Pueblos Indígenas, AG/RES.2888 (XLVI-O/16) (2016), Recuperado de http://cdn7.iitc.org/wp-content/uploads/AG07150E06_web.pdf

Declaración de las Naciones Unidas sobre los derechos de los pueblos indígenas (2007) Recuperado de http://www.un.org/esa/socdev/unpfii/documents/DRIPS_es.pdf

Engle, K. (2011) On Fragile Architecture: The UN Declaration on the Rights of Indigenous Peoples in the Context of Human Rights. The European Journal of International Law, vol. 22, N.1

Kichwa Sarayaku vs. Ecuador (2012) Recuperado de http://www.corteidh.or.cr/docs/casos/articulos/seriec_245_esp.pdf

Montevideo Convention of the Rights and Duties of States. Montevideo, (1933) Recuperado de http://www.ilsa.org/jessup/jessup15/Montevideo\%20Convention.pdf

Nettheim, G. (1988) Peoples and Populations-Indigenous peoples and the Rights of Peoples. The Rights of Peoples. Ed. By James Crawford, Oxford: Clarendon Press

Rouland, N., Pierré-Caps, S., Poumarede, J. (1999) Derechos de las minorias y de los pueblos autóctonos, Madrid: Siglo Veintiuno editores.

Saramaka vs.Surinam. (2007) Recuperdo de http://www.corteidh.or.cr/docs/casos/articulos/seriec_172_esp.pdf

Schwebel, S.M. (1996) The treatment of human rights and of aliens in the International Court of Justice. Fifty years of the International Court of Justice. Essays in honour of Sir Robert Jennings. Cambrige University Press.

Spaulding R. (1997) Peoples as National Minorities: A Review of Will Kymlicka's Arguments for Aboriginal Rights from a Self-Determination Perspective. The University of Toronto Law Journal. Vol.7, № 1.

Swepston (1989) Indigenous and Tribal Peoples and International Law. Recent Developments // Current Anthropology, Vol. 30. № 2.

Xákmok Kásek vs. Paraguay (2010) Recuperdo de https://www.escr-net.org/caselaw/2014/caseindigenous-community-xakmok-kasek-v-paraguay 